\title{
Binding of Serotonin to Lipid Membranes
}

Peters, Günther H.J.; Wang, Chunhua; Cruys-Bagger, Nicolaj; Velardez, Gustavo; Madsen, Jesper Jonasson; Westh, Peter

Published in:

Journal of the American Chemical Society

Link to article, DOI:

10.1021/ja306681d

Publication date:

2013

Document Version

Publisher's PDF, also known as Version of record

Link back to DTU Orbit

Citation $(A P A)$ :

Peters, G. H. J., Wang, C., Cruys-Bagger, N., Velardez, G., Madsen, J. J., \& Westh, P. (2013). Binding of Serotonin to Lipid Membranes. Journal of the American Chemical Society, 135(6), 2164-2171.

https://doi.org/10.1021/ja306681d

\section{General rights}

Copyright and moral rights for the publications made accessible in the public portal are retained by the authors and/or other copyright owners and it is a condition of accessing publications that users recognise and abide by the legal requirements associated with these rights.

- Users may download and print one copy of any publication from the public portal for the purpose of private study or research.

- You may not further distribute the material or use it for any profit-making activity or commercial gain

- You may freely distribute the URL identifying the publication in the public portal

If you believe that this document breaches copyright please contact us providing details, and we will remove access to the work immediately and investigate your claim 


\section{Binding of Serotonin to Lipid Membranes}

Günther H. Peters, ${ }^{* \dagger}$ Chunhua Wang, ${ }^{\ddagger}$ Nicolaj Cruys-Bagger, ${ }^{\ddagger}$ Gustavo F. Velardez, ${ }^{\dagger}$ Jesper J. Madsen, ${ }^{\dagger}$ and Peter Westh* ${ }^{*}+$

${ }^{\dagger}$ Department of Chemistry, Technical University of Denmark, 2800 Kgs. Lyngby, Denmark

${ }^{\ddagger}$ NSM, Research Unit for Functional Biomaterials, Roskilde University, 4000 Roskilde, Denmark

\section{Supporting Information}

ABSTRACT: Serotonin (5-hydroxytryptamine, 5-HT) is a prevalent neurotransmitter throughout the animal kingdom. It exerts its effect through the specific binding to the serotonin receptor, but recent research has suggested that neural transmission may also be affected by its nonspecific interactions with the lipid matrix of the synaptic membrane. However, membrane-5-HT interactions remain controversial and superficially investigated. Fundamental knowledge of this interaction appears vital in discussions of putative roles of 5$\mathrm{HT}$, and we have addressed this by thermodynamic measurements and molecular dynamics (MD) simulations. 5-HT was found to interact strongly with lipid bilayers (partitioning coefficient $\sim 1200$ in mole fraction units), and this is highly unusual for a hydrophilic solute like 5-HT which has a bulk, oilwater partitioning coefficient well below unity. It follows that membrane affinity must rely on specific interactions, and the MD simulations identified

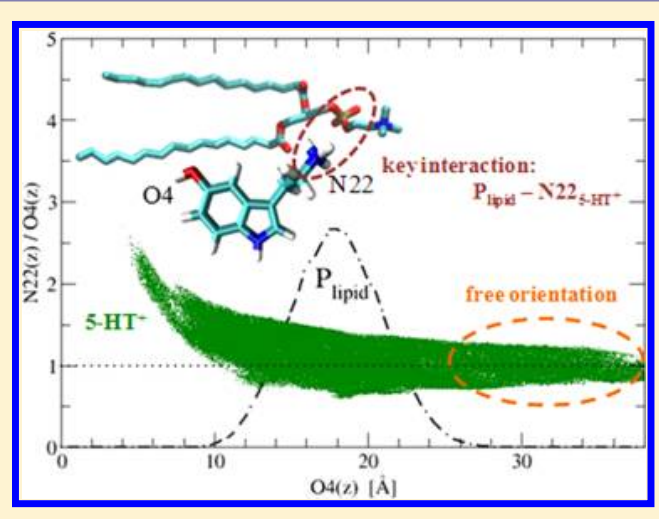
the salt-bridge between the primary amine of 5-HT and the lipid phosphate group as the most important interaction. This interaction anchored cationic 5-HT in the membrane interface with the aromatic ring system pointing inward and a prevailing residence between the phosphate and the carbonyl groups of the lipid. The unprotonated form of 5-HT shows the opposite orientation, with the primary amine pointing toward the membrane core. Partitioning of 5-HT was found to decrease lipid chain order. These distinctive interactions of 5-HT and model membranes could be related to nonspecific effects of this neurotransmitter.

\section{INTRODUCTION}

Knowledge of the interaction of small molecules with lipid membranes and their bilayer distribution is of great pharmacological importance and represents an active field of current biophysical research. ${ }^{1}$ Pharmacologically active molecules (drugs) are often targeting transmembrane proteins, and it has been proposed that the plasma membrane can serve as a reservoir for small molecules and thereby facilitate binding of these molecules to the target protein. ${ }^{2}$ The underlying mechanism is that interfacial binding to or partitioning into the membrane will bring the drug molecule in close proximity to its target, and consequently, the interaction probability between drug molecule and target transmembrane protein will increase. ${ }^{2}$ The plasma membrane has also been proposed as a primary target for general anesthetics. Their action may rely on direct binding to postsynaptic ligand-gated ion channels (LGICs) or an indirect effect, mediated through absorption into the postsynaptic bilayer membrane. ${ }^{3-6}$ Recently, the crystal structures of complexes of the anesthetics propofol and desflurane with bacterial Gloeobacter violaceus pentameric LGIC have been solved. ${ }^{3}$ These structures revealed a generalanesthetic cavity, which is accessible from the lipid bilayer. Propofol was found to bind at the entrance of the cavity, whereas the smaller, more flexible desflurane binds deeper inside. Conversely, indirect effects of anesthetic partitioning will alter the biophysical properties of the bilayer and thus affect the function of the LGICs. ${ }^{5,7-9}$ The best documented nonspecific lipid-protein interactions are based on so-called lipid-protein hydrophobic mismatch, ${ }^{10,11}$ i.e., a mismatch between the hydrophobic length of the protein and the hydrocarbon thickness of the surrounding lipid bilayer. These proteinbilayer hydrophobic interactions may cause lipid packing stress, and protein function modulation could result from coupling protein conformational changes to elastic deformations of the surrounding bilayer membrane. ${ }^{11,12}$ This has been experimentally observed for $\gamma$-aminobutyric acid type A $\left(\mathrm{GABA}_{\mathrm{A}}\right)$, glycine, and $\mathrm{N}$-methyl-D-aspartate (NMDA) receptors, where their function can be modulated by membrane-active amphiphiles such as surfactants, Triton-X, benzodiazepines, barbiturates, long-chain alcohols, and anesthetics. ${ }^{12-14}$ Sonner and co-workers provided evidence that LGICs' function can be modulated by co-released neurotransmitters in a fashion similar to that observed for anesthetics. ${ }^{15}$ The authors studied the inhibitory glycine and $\mathrm{GABA}_{\mathrm{A}}$ receptors and the excitatory NMDA receptor and showed that NMDA receptor function is inhibited by acetylcholine, whereas glycine and $\mathrm{GABA}_{\mathrm{A}}$ receptor function is enhanced by respectively $\gamma$-aminobutyric

Received: July 9, 2012

Published: January 11, 2013 
acid and glycine. The authors suggest an anesthetic-like mechanism of neurotransmitters, where the molecules modulate bilayer properties. LGIC receptors are adapted to these changes and use them to regulate their conformational equilibrium. Moreover, a membrane-mediated mechanism has also been suggested for polyhydric alkanols that exhibit anesthetic potency in tadpoles. ${ }^{16}$

These studies indicated that, beyond binding of the neurotransmitters to their LGIC receptors, the receptor can also be modulated indirectly by changes in membrane properties. Clearly, these two mechanisms may not be exclusive, and depending on LGIC receptor, both mechanisms may contribute to the physiological action of the neurotransmitter. Experimental studies of the thermodynamics and membrane partitioning of neurotransmitters are limited. ${ }^{17,18}$ Due to the complex nature of a biological membrane and its lipid-water interface, simple partition experiments in water/ octanol biphasic systems do not provide information on the distribution of a molecule in the inhomogeneous bilayer environment or its effect on lipid properties. More structurebased biophysical methods are required to understand the interactions of small molecules with membrane interfaces. Molecular dynamics (MD) simulations are a powerful tool to provide insight on the molecular scale, ${ }^{19-21}$ and the technique has been used extensively to study a wide range of solutes and their interactions with different kinds of lipid membranes. ${ }^{22-29}$ In the present study, MD simulations in combination with thermodynamic measurements are applied to study the interaction of 5-HT with phosphocholine (PC) bilayer membranes. Our results show that serotonin interacts strongly with PC bilayers. The charged primary amine group interacts predominately with the PC phosphate group. This interaction serves as an anchor, placing the primary amine group in the interfacial plane and the aromatic ring system into the bilayer. 5-HT is not able to cross the bilayer membrane mainly due to two contributions: the aliphatic amino group in 5-HT acts as an anchor to the interfacial bilayer plane, and the flexibility of the phospholipid alkyl chain tails provides an entropic barrier for serotonin to cross the center of the bilayer membrane.

\section{EXPERIMENTAL AND COMPUTATIONAL PROCEDURES}

Simulations. MD simulations were performed for a single serotonin (5-hydroxytryptamine, 5-HT; Figure 4) molecule together with a phospholipid bilayer consisting of pure 1,2-dipalmitoyl-snglycero-3-phosphocholine (DPPC) or pure 1,2-dioleoyl-sn-glycero-3phosphocholine (DOPC). 5-HT has two $\mathrm{pH}$-sensitive groups (see Figure 4): the aliphatic amino group (N22) and the aromatic hydroxyl moiety $(\mathrm{O} 4){ }^{30,31}$ Since the primary amino group has $\mathrm{p} K_{\mathrm{a}}=9.97$, we have considered both the charged and neutral forms of serotonin (hereafter named $5-\mathrm{HT}^{+}$and $5-\mathrm{HT}^{n}$, respectively). The bilayers consisted of 72 phospholipid molecules (36 per leaflet), fully hydrated with 3319 water molecules ( $\sim 46$ water molecules per lipid molecule), and the center of mass of the bilayer was located at $x=y=z=0 \AA$, with $z$ being the direction normal to the bilayer plane. The DOPC bilayer was constructed from a DPPC bilayer. We conducted three simulations (each $\sim 120 \mathrm{~ns}$ ) for DOPC $/ 5-\mathrm{HT}^{+}$, four simulations (each 70-80 ns) for DPPC $/ 5-\mathrm{HT}^{+}$, and four simulations (each $60-70 \mathrm{~ns}$ ) for DPPC $/ 5-\mathrm{HT}^{n}$. The first 5 and $20 \mathrm{~ns}$ of respectively each DPPC/5$\mathrm{HT}^{+, n}$ and DOPC/5- $\mathrm{HT}^{+}$simulation (corresponding to the equilibration of the area/lipid molecule) were discarded from further analyses. In comparison to DOPC, shorter simulations were required for $\mathrm{DPPC} / 5-\mathrm{HT}^{+, n}$, since the initial configuration of the DPPC bilayer membrane was taken from a previous study. ${ }^{32}$ The initial position of the serotonin molecule was chosen such that the molecule was placed at different distances away from the interfacial plane of the bilayer membrane using the VMD 1.8.7 software package. ${ }^{33}$ Water molecules that were within $2.4 \AA$ of the serotonin molecule were deleted using VMD. To neutralize the charged systems DPPC/5- $\mathrm{HT}^{+}$and DOPC/ $5-\mathrm{HT}^{+}$, one water molecule in each system was randomly picked and replaced with a chloride ion. The force field parameters, including partial charges for $5-\mathrm{HT}^{+}$, were adapted from a previous study. ${ }^{34,35}$ The partial charges of the primary amine group of $5-\mathrm{HT}^{n}$ were taken from the lysine residue force field parameters given by the CHARMM27 force field. ${ }^{36}$ Simulations were performed using the NAMD 2.5 software package with a modified CHARMM27 force field for DPPC and the TIP3P water model..$^{32,37,38}$ We previously reparametrized the force field for the DPPC headgroup region based on the experimental data from Nagle and co-workers. ${ }^{39}$ We used the same parameters for the DOPC bilayer. Simulations were carried out in the NPT ensemble at constant pressure $(P=1 \mathrm{~atm})$ and temperature $(T=$ $323 \mathrm{~K}$ for DPPC and $T=303 \mathrm{~K}$ for DOPC system), applying periodic boundary conditions and using the particle mesh Ewald method for calculating the long-range electrostatic forces. ${ }^{40}$ Simulations were carried out using parameters described previously ${ }^{32,41}$ and listed in the Supporting Information. In addition to these simulations, we conducted simulations with umbrella sampling and used the weighted histogram analysis method (WHAM) to assess the potential of mean force (PMF) along the bilayer normal. ${ }^{42-45}$ These procedures are also described in more detail in the Supporting Information.

Materials. Serotonin hydrochloride (5-HT) (>98\%, powder, Sigma-Aldrich), 1,2-dimyristoyl-sn-glycero-3-phosphocholine (DMPC), and DOPC (99\%, power, Avanti Polar Lipids) were used as received.

Preparation Unilamellar Vesicles. DMPC or DOPC was hydrated with freshly prepared Milli- $Q$ water to give multilamellar vesicles (MLVs) with a concentration about $2 \%(\mathrm{w} / \mathrm{w})$. The MLVs were further hydrated and then extruded into $100 \mathrm{~nm}$ unilamellar vesicles (ULVs) as described previously. ${ }^{18,46}$ The final lipid concentration was measured gravimetrically to within $\pm 0.02 \% .{ }^{47}$ The choice of DMPC membranes for the experiments and DPPC membranes in the simulations was based on technical restrictions: the dialysis equipment cannot operate at the higher main transition temperature of DPPC. It has previously been shown in MD simulations that DMPC and DPPC have many common features, resulting in indistinguishable interfacial properties. ${ }^{48}$ Moreover, the interaction of 5-HT with the two types of lipids appears to be equivalent inasmuch as the change in DMPC transition temperature found here (Figure 1) is equivalent to that previously reported for 5HT/DPPC. ${ }^{49}$ Therefore, a direct comparison of DMPC and DPPC appears to be reasonable.

Dialysis and HPLC. The affinity of serotonin for lipids (DMPC or DOPC) was assessed by dialysis equilibrium measurements as described elsewhere. ${ }^{46,50}$ The equilibrium, molal concentration of 5HT inside and outside the dialysis bag ( ${ }^{\text {in }} m_{5-\mathrm{HT}}$ and ${ }^{\text {out }} m_{5-\mathrm{HT}}$, respectively), and lipid concentration inside the dialysis bag were measured by HPLC (Varian 9012, Santa Clara, CA) equipped with an evaporative light scattering detector (Sedex85, Sedere, France), UV detector (Varian 9050), and an Aquity C18 column. The eluent was methanol:1-propanol:water (6:4:1), which completely dissolved the vesicles during the analysis. The difference in serotonin concentration across the dialysis membrane $\left(\Delta m_{5-\mathrm{HT}}\right)$ in molal units (i.e., mol per $\mathrm{kg}$ water) was calculated according to $\Delta m_{5-\mathrm{HT}}={ }^{\text {in }} m_{5-\mathrm{HT}}-{ }^{\text {out }} m_{5-\mathrm{HT}}$. The outside concentration, ${ }^{\text {out }} m_{5-\mathrm{HT}}$, was derived directly from the raw HPLC data and an appropriate standard curve. Samples from inside the bag contained both aqueous solution and $(\sim 2 \%)$ lipid, and the raw HPLC signal was divided by $\left(1-w_{2}\right)$, where $w_{2}$ is the weight fraction of lipid, to obtain the 5-HT concentration in molal units. ${ }^{46,50}$

Differential Scanning Calorimetry (DSC). The effect of serotonin on the phase behavior of DMPC was measured on a Nano-Differential Scanning Calorimeter III (TA Instruments, New Castle, DE). The samples were prepared volumetrically from a stock DMPC (ULV) and stock serotonin solution to always give the same concentration of DMPC $\left(3.8 \mathrm{mmol} / \mathrm{kg} \mathrm{H}_{2} \mathrm{O}\right)$. Transmembrane equilibration of 5-HT was obtained through temperature cycling 
around the main transition temperature. Degassed sample (serotonin and DMPC) and reference (aqueous serotonin) solutions were loaded into the DSC and heated at $0.1{ }^{\circ} \mathrm{C} / \mathrm{min}$ from 12 to $32{ }^{\circ} \mathrm{C}$. Three scans were performed on each sample. The uncertainty in the maximum of the transition peak was $0.02{ }^{\circ} \mathrm{C}$.

\section{RESULTS AND DISCUSSION}

Experiments. Two issues appear critical in the discussion of the membrane matrix as a putative target for 5-HT: (i) what is the net affinity of 5-HT for lipid membranes (i.e., does it partition into the membrane or not), and (ii) is membrane partitioning (if any) driven by hydrophobic effects, or does 5HT make favorable polar contacts with moieties of the phospholipid molecules? With respect to question (i), we used dialysis equilibrium measurements to provide a model-free measure of the net affinity.

Results in Figure 1 show that the concentration difference, $\Delta m_{5-\mathrm{HT}}$ (see Experimental and Computational Procedures),

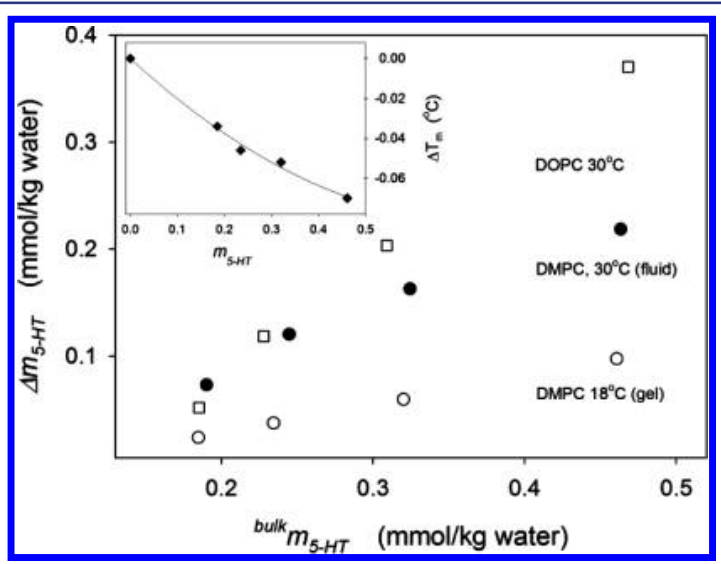

Figure 1. Main panel: results from dialysis equilibrium measurements. The concentration difference, $\Delta m_{5-\mathrm{HT}}$ (see Experimental and Computational Procedures), is plotted as a function of the bulk 5HT concentration, measured in the reservoir outside the dialysis bag. Positive values of $\Delta m_{5-\mathrm{HT}}$ specify attractive membrane-serotonin interactions. Inset: effect of 5-HT on the main transition temperature of DMPC measured by DSC. The abscissa in the inset is the total (bound + aqueous) 5-HT concentration.

was consistently positive, and this specifies attractive interactions. For DMPC (in both the gel and fluid states), the increase in $\Delta m_{5-\mathrm{HT}}$ was nearly proportional to the free (aqueous) 5-HT concentration, ${ }^{\text {out }} m_{5-\mathrm{HT}}$, and this behavior is in line with a conventional partitioning picture. The partitioning coefficient in molal concentration units, $K_{\mathrm{p}, \mathrm{m}}=$ ${ }_{\text {mem }} m_{5-\mathrm{HT}} /{ }^{\mathrm{aq}} m_{5-\mathrm{HT}}$, where superscripts "mem" and "aq" signify the membrane and aqueous bulk, respectively, can be calculated from the data in Figure 1. Thus, the molal concentration of 5$\mathrm{HT}$ in the membrane (i.e., mmol of 5-HT partitioned per $\mathrm{kg}$ lipid) is ${ }^{\mathrm{mem}} m_{5-\mathrm{HT}}=R_{\mathrm{w}: 1} \Delta m_{5-\mathrm{HT}}$, where $R_{\mathrm{w}: 1}$ is the water:lipid mass ratio in the dialysis bag. For DMPC, the $K_{\mathrm{p}, \mathrm{m}}$ values were respectively $32 \pm 2$ (fluid phase, $30^{\circ} \mathrm{C}$ ) and $12 \pm 4$ (gel phase, $\left.18{ }^{\circ} \mathrm{C}\right)$. In mole fraction units, this translates into coefficients $\left(K_{\mathrm{p}, \mathrm{x}}\right)$ of respectively $1.2 \times 10^{3}$ and $4.4 \times 10^{2}$. For DOPC, the results in Figure 1 show positive curvature, which implies that the affinity for 5-HT rises as the membrane is increasingly perturbed by the solute. We do not have data to elucidate the origin of this behavior, but note that in the lower part of the concentration range investigated here $(<\sim 0.3 \mathrm{mmol} / \mathrm{kg}$ water $)$ the affinity of 5-HT for DOPC is comparable to that for
DMPC. Earlier reports on the net affinity of 5-HT for lipid bilayers are divisive. Fluorescence measurements suggested no significant binding or partitioning to membranes composed of either POPC or POPC/POPG mixtures. ${ }^{51}$ Other works found that 5-HT lowered the main transition temperature, $T_{\mathrm{m}}$, of saturated PC, and ascribed this to an interaction. ${ }^{49,52} \mathrm{We}$ conducted DSC measurements on DMPC and found a clear reduction in $T_{\mathrm{m}}$ (inset of Figure 1), even for the sub-millimolal 5 -HT concentrations used here. This is qualitatively in line with the dialysis results, as a stronger interaction with the fluid membrane (filled circles in Figure 1) will favor this state over the gel (open circles) and hence lower the transition temperature. The calorimetric data may be analyzed quantitatively if we apply a solid solution freezing point depression model. ${ }^{53}$ As shown in the Supporting Information, the initial slope in the inset of Figure 1 translates into a $K_{\mathrm{p}, \mathrm{x}}$ value of about 700 for fluid DMPC. This value is based on a number of approximations and cannot be considered accurate (see Supporting Information), but its order of magnitude corresponds to the (more precise) result from the dialysis measurement, and the DSC measurements thus support the conclusion that 5-HT interacts strongly with the bilayers. The interaction of 5-HT is strong compared to those of other small, cyclic compounds such as benzyl alcohol and cyclohexanol, which have $K_{\mathrm{p}, \mathrm{x}}$ values of 300-400 for fluid DMPC. ${ }^{54}$ The extent of partitioning for 5-HT is comparable to that of highly hydrophobic compounds such as 1-hexanol $\left(K_{\mathrm{p}, \mathrm{x}} \approx 8-900\right)$ or 1-heptanol $\left(K_{\mathrm{p}, \mathrm{x}} \approx 2-4000\right) .{ }^{55,56}$ For these latter molecules, the membrane partitioning coefficients are similar to bulk ("oilwater") partitioning coefficients, ${ }^{57,58}$ and this suggests that partitioning is essentially driven by a hydrophobic expulsion from the aqueous phase, while direct interactions in the membrane are less important. ${ }^{59,60}$ This is in strong contrast to 5-HT, which has a bulk partitioning coefficient about 3 orders of magnitude lower ${ }^{49,61,62}$ than the values found here for fluid PC bilayers. Most recently, Tatsumi and Ueda ${ }^{63}$ used precise electrochemical methods to show that the partitioning coefficient between water and nitrobenzene for the cationic form of 5-HT (which dominates at neutral $\mathrm{pH}$ ) was as low as 0.007. We conclude that 5-HT interacts strongly with PC membranes, and in light of its hydrophilic nature (manifested in low bulk partitioning), the affinity must involve strong contact interactions with the lipid (cf. question (ii) above). Although some affinity for lipid membranes has been found for other polar neurotransmitters, ${ }^{18}$ the strength of the PC-5-HT interaction appears unusual for a hydrophilic compound. Below, we investigate this by MD simulations.

Simulations. Simulations of pure DPPC and DOPC bilayers (i.e., with no 5-HT) showed surface areas and order parameter profiles (Figures S1, S2, Supporting Information) in good accordance with previously reported simulation results and experimental values. ${ }^{32,64-70}$ These tests are described in some detail in the Supporting Information. Here, we are interested in the effects of adding 5-HT, and we first note that 5-HT contains a primary amino group (N22) and an aromatic hydroxyl moiety (O4) (cf. Figure 4), with $\mathrm{pK}$ a values of respectively 9.97 and $10.73 . .^{30,31}$ Hence, 5-HT is cationic around neutral $\mathrm{pH}^{63}$ However, the low dielectric constant environment inside the membrane could favor the neutral form of 5-HT. Shifts in $\mathrm{p} K_{\mathrm{a}}$ in response to local environments are well documented ${ }^{71-73^{a}}$ and seen for example for oleic acid, which increases $\mathrm{p} K_{\mathrm{a}}$ from 5 to 7.6 upon transfer from water to a phosphatidylcholine membrane. ${ }^{74}$ We therefore studied the 
interactions of both the charged $\left(5-\mathrm{HT}^{+}\right)$and neutral $\left(5-\mathrm{HT}^{n}\right)$ forms of serotonin with DPPC. To investigate the interfacial behavior of serotonin in unsaturated lipid bilayers, we also considered the DOPC/5- $\mathrm{HT}^{+}$system.

Serotonin-Bilayer Interactions. The structural properties of the bilayers and the absorption behavior of 5-HT were extracted from the positional probability distributions of selected atoms of the phospholipids, the hydroxyl oxygen atom in 5-HT $\left(\mathrm{O}_{5-\mathrm{HT}}\right)$ and the oxygen atom in water $(\mathrm{W})$. The selected lipid atoms are the phosphorus atom $\left(\mathrm{P}_{\text {lipid }}\right)$ in the phosphate group, the nitrogen $\left(\mathrm{N}_{\text {lipid }}\right)$ in the choline group, the carbonyl carbon of the ester group ( $\mathrm{Cl}_{\text {lipid }}$, glycerol backbone), and the methyl group $(\mathrm{C} 16 / \mathrm{C} 18$, tail).The atoms chosen are displayed in Figures 2 and 3 for phospholipid and in Figure 4 for 5-HT. The profiles are shown in Figures 2 and 3 for respectively DPPC $/ 5-\mathrm{HT}^{+, n}$ and $\mathrm{DOPC} / 5-\mathrm{HT}^{+}$.

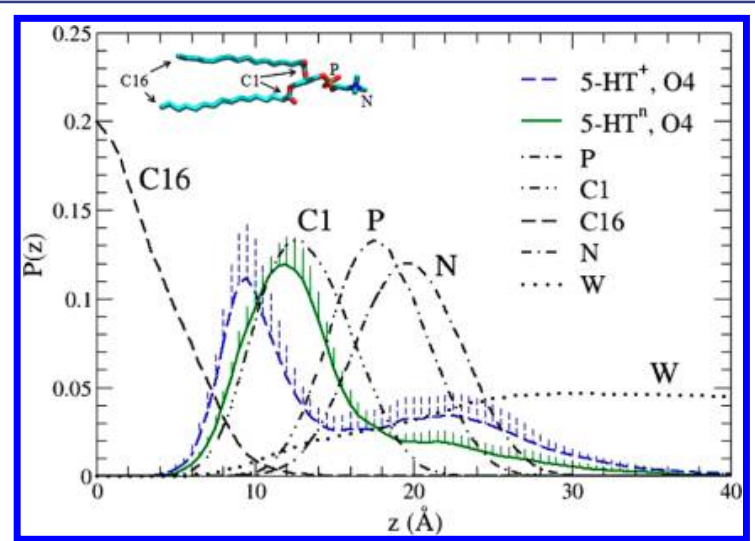

Figure 2. Positional probability distribution for selected groups along the bilayer normal, $z$, averaged over the last $\sim 70$ ns of each MD trajectory and over the multiple trajectories of either DPPC $/ 5-\mathrm{HT}^{+}$or DPPC $/ 5-\mathrm{HT}^{n}$ simulations. Profiles for the phospholipid atom $\mathrm{P}_{\text {lipid }}$ (phosphate group), $\mathrm{N}_{\text {lipid }}$ (choline group), $\mathrm{Cl}_{\text {lipid }}$ (carbonyl carbon of glycerol backbone), and C16 $6_{\text {lipid }}$ (carbon in the methyl group, tail) are shown along with the profiles for water molecules $\left(\mathrm{W}_{\text {water }}\right)$ and $\mathrm{O} 4_{5-\mathrm{HT}}$ (oxygen of the hydroxyl group of 5-HT). Error bars represent SEM for the four independent simulations. The center of mass of the bilayer is located at $z=0$. Phospholipid and neurotransmitter structures showing the atom types are displayed in the insets of Figures 2 and 4, respectively.

The profiles for the phospholipid atoms and water molecules resemble similar features that are generally observed in PC bilayers, i.e., penetration of water molecules into the lipid headgroup region, broad $\mathrm{P}_{\text {lipid }}$ and $\mathrm{N}_{\text {lipid }}$ profiles with a full width at half-maximum $\sim 8 \AA$, and flexible lipid tails (cf. refs 75 , 76). Interestingly, both $5-\mathrm{HT}^{+}$and $5-\mathrm{HT}^{n}$ are able to enter the bilayer membrane independently of the saturation of the phospholipids. The highest probability for observing 5-HT is in the headgroup region, that is, between the glycerol backbone $\left(\mathrm{Cl}_{\text {lipid }}\right)$ and the choline $\left(\mathrm{N}_{\text {lipid }}\right)$ group. The 5-HT profiles are relatively broad, reflecting the mobility of 5-HT in the bilayer. There is a clear difference in the distributions of $5-\mathrm{HT}^{+}$when compared to $5-\mathrm{HT}^{n}$ (Figure 2), and when the results for $\mathrm{DPPC} / 5-\mathrm{HT}^{+}$and DOPC $/ 5-\mathrm{HT}^{+}$are compared. In DPPC, the neutral species penetrate on average deeper into the bilayer than $5-\mathrm{HT}^{+}$. For DOPC, the $5-\mathrm{HT}^{+}$profile is broader (Figure 3 ), with a weak tendency to show two maxima. This tendency is also indicated in the PMF data (Figure S6). Notably, there is a higher probability of $5-\mathrm{HT}^{+}$to enter deeper into the DPPC

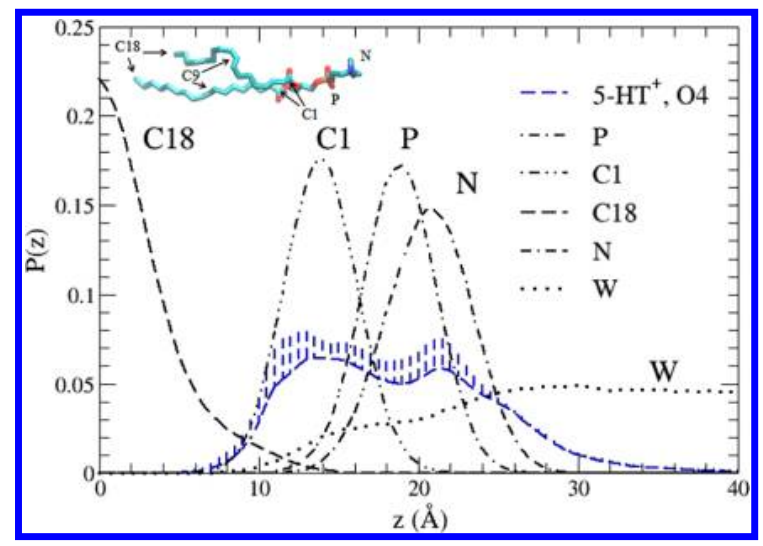

Figure 3. Positional probability distribution for selected groups along the bilayer normal, $z$, averaged over the last $\sim 100 \mathrm{~ns}$ of each MD trajectory and over the multiple trajectories of DOPC/5- $\mathrm{HT}^{+}$ simulations. C18 $8_{\text {lipid }}$ corresponds to the methyl group of the lipid fatty acid chain (tail); error bars and other groups are specified in Figure 2.

bilayer membrane than observed for the DOPC bilayer ( 0.11 vs 0.04 at $z \sim 10 \AA)$.

This is further supported by Figure 4, where we have plotted the ratio $\mathrm{N} 22_{5-\mathrm{HT}}(z) / \mathrm{O}_{5-\mathrm{HT}}(z)$ as a function of $\mathrm{O}_{5-\mathrm{HT}}(z)$ for $\mathrm{DPPC} / 5-\mathrm{HT}^{+, n}$. Similar results were observed for DOPC/5$\mathrm{HT}^{+}$(data not shown).

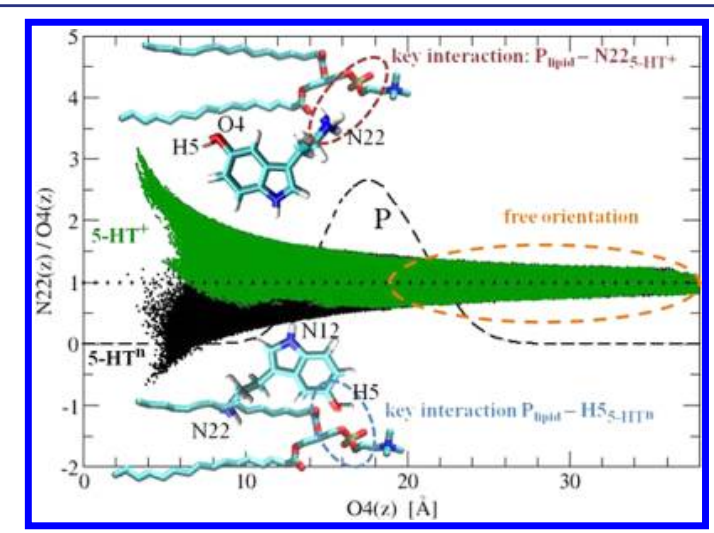

Figure 4. Scatter plot of the ratio of $\mathrm{N} 22_{5-\mathrm{HT}}(z)$ and $\mathrm{O} 4_{5-\mathrm{HT}}(z)$ position as a function of $\mathrm{O}_{5-\mathrm{HT}}(z)$ position. The $z$-axis is along the bilayer normal, and the center of mass of the bilayer is located at $z=0$. Black, DPPC $/ 5-\mathrm{HT}^{n}$; green, DPPC $/ 5-\mathrm{HT}^{+}$. As a reference, the probability distribution, $\mathrm{P}_{\text {lipid }}$ is included (see Figure 2 for details). $\mathrm{P}_{\text {lipid }}$ is scaled by a factor of 20 ( $y$-axis) to show it on the same plot. The graph specifies the orientation of 5-HT and schematically shows the specific interactions observed between lipid and 5-HT. In the water phase, free orientation is observed, whereas depending on the protonation state of 5-HT, two distinct orientations of 5-HT are seen. Top: $5-\mathrm{HT}^{+}$; primary amino group points to the bilayer water interface. Key interaction: $\mathrm{P}_{\text {lipid }}-\mathrm{N} 22_{5-\mathrm{HT}}$. Bottom: $5-\mathrm{HT}^{n}$; primary amino group points into the bilayer region. Key interaction: $\mathrm{P}_{\text {lipid }}-$ $\mathrm{H} 5_{5-\mathrm{HT}}$.

$\mathrm{N} 22_{5-\mathrm{HT}}(z)$ and $\mathrm{O}_{5-\mathrm{HT}}(z)$ are respectively the hydroxyl oxygen position and the aliphatic amino group position along the bilayer normal. Profiles for $\mathrm{O}_{5-\mathrm{HT}}(z)$ as a function $\mathrm{N} 22_{5-\mathrm{HT}}(z)$ are provided in Figures S3 and S4 (Supporting Information) for respectively DPPC $/ 5-\mathrm{HT}^{+, n}$ and DOPC $/ 5$ $\mathrm{HT}^{+}$. The positional probability distribution, $\mathrm{P}_{\text {lipid }}(z)$, is also included as a reference in Figure 4, and the horizontal dotted 
line in the figure corresponds to an orientation of 5-HT where $\mathrm{O} 4_{5-\mathrm{HT}}(z)$ and $\mathrm{N} 22_{5-\mathrm{HT}}(z)$ would be at the same $z$-position. In the water phase, an evenly distributed band around the dashed line is observed, indicating 5-HT can freely rotate (see also Figures S3 and S4). 5-HT orientation becomes restricted only when 5-HT enters the interfacial region and reaches the glycerol backbone (corresponding to the maximum in $\mathrm{Cl}_{\text {lipid }}$; Figure 2). Here, $5-\mathrm{HT}^{+}$favors an orientation where the charged primary amino group points to the bilayer water interface (Figure 4, top). In contrast, for $5-\mathrm{HT}^{n}$, the aliphatic amino group points to the center of the bilayer (Figure 4, bottom), and the hydroxyl group ( $\mathrm{H} 5-\mathrm{O} 4)$ points to the interfacial bilayer plane. It appears that, due to the loss of the charge on $\mathrm{N} 22_{5-\mathrm{HT}}$, it is energetically more favorable to align the carbon chain of 5-HT ${ }^{n}$ with the phospholipid alkyl chain. To test whether this opposite orientation of respectively $5-\mathrm{HT}^{n}$ and 5$\mathrm{HT}^{+}$could be related to poor convergence, we conducted a simulation where the charge status of $\mathrm{N} 22_{5-\mathrm{HT}}$ was changed intermittently. The results (Figure S7) confirmed the chargedependent turnover of 5-HT and suggested that relaxation to the preferred orientation could be captured in simulations of the current length. For the charged 5-HT species and independent of the saturation of the phospholipids, the interactions between the charged $\mathrm{N} 22_{5-\mathrm{HT}}$ group and (as discussed below) the phosphate group are strong enough to force the aromatic ring system into the alkyl chain part of the phospholipids. Clearly, for the 5-HT orientation, there is a balance between electrostatic interactions (charged species) and entropic contribution (neutral species). The positional probability distributions for 5-HT also overlap with the distributions of the phospholipid methyl groups (tails) (Figures 2 and 3). Hence, two contributions may prevent deeper penetration of serotonin into the bilayer: first, the favorable interactions of the aliphatic amino group with the phosphate group and second, the flexibility of the methyl group. Taken together with the experimental data (Figure 1), this suggests that 5-HT is characterized by a high partitioning but low permeability, and this is unusual for a small solute. This picture is further supported by the simulations with umbrella sampling. Thus, the PMF data in Figure S6 show a large free energy barrier for membrane permeation and a minimum for the center of mass of $5-\mathrm{HT}^{+}$in the $z=12-16 \AA$ range. This preferred depth compares favorably with the maximum probability of $\mathrm{O} 4$ around $z=10-13 \AA$ found in Figures 2 and 3 (the difference in the two approaches simply reflects the distance $(\sim 3.6 \AA)$ between the center of mass and O4). The PMF analysis suggests a free energy change for the bulkmembrane transfer of $5-\mathrm{HT}$ of -10 to $-15 \mathrm{~kJ} / \mathrm{mol}$, and this is in reasonable accordance with the experimental result, $\Delta G^{\circ}=$ $-R T \ln K_{\mathrm{p}, \mathrm{m}}=-9.0 \pm 0.4 \mathrm{~kJ} / \mathrm{mol}$.

To further quantify key interactions between lipid and neurotransmitter, we determined the minimum distance $\left(d_{\min }\right)$ between selected phospholipids and 5-HT atoms along the trajectories and calculated the probability distribution functions, $P\left(d_{\text {min }}\right)$. The most important $P\left(d_{\text {min }}\right)$ 's are between $\mathrm{P}_{\text {lipid }}, \mathrm{N}_{\text {lipid }}$ and $\mathrm{N} 12_{5-\mathrm{HT}}, \mathrm{N} 22_{5-\mathrm{HT}}, \mathrm{H} 5_{5-\mathrm{HT}}$. Location of the atoms in the lipid and 5-HT structure are shown in Figures 2 and 4, respectively. $P\left(d_{\text {min }}\right)$ values for $\mathrm{P}_{\text {lipid }}-5-\mathrm{HT}$ and $\mathrm{N}_{\text {lipid }}-5$ - $\mathrm{HT}$ are displayed in Figure 5 and Figure S5, respectively, for DPPC/5$\mathrm{HT}^{+}$(left), DOPC $/ 5-\mathrm{HT}^{+}$(middle), and DPPC/5- $\mathrm{HT}^{n}$ (right).

In Figure 5, only a narrow range of $d_{\text {min }}$ is displayed to emphasize the difference in interactions. Corresponding $P\left(d_{\text {min }}\right)^{\prime}$ for $2 \AA \leq d_{\text {min }} \leq 9 \AA$ are provided in Figure S5. For

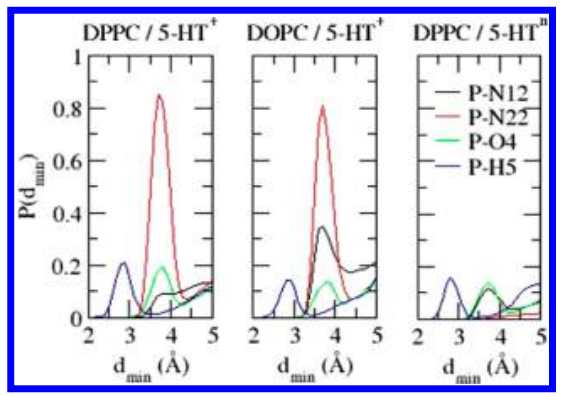

Figure 5. Zoom-in of the probability distributions of minimum distance, $P\left(d_{\text {min }}\right)$, between $\mathrm{P}_{\text {lipid }}$ and selected 5-HT atoms (N12, N22, $\mathrm{O} 4$, and H5) extracted from the DPPC/5- $\mathrm{HT}^{+}$(left), DOPC/5- $\mathrm{HT}^{+}$ (middle), and DPPC $/ 5-\mathrm{HT}^{n}$ (right) systems. For $5-\mathrm{HT}^{+}$, the most important interaction is between $\mathrm{P}_{\text {lipid }}$ and $\mathrm{N} 22_{5-\mathrm{HT}}\left(P\left(d_{\text {min }} \approx 3.7 \AA\right.\right.$, $\left.\left.\mathrm{N} 22_{5-\mathrm{HT}}\right)_{\text {maximum }} \approx 0.8-0.9\right)$, followed by $\mathrm{P}_{\text {lipid }}-\mathrm{H} 5_{5-\mathrm{HT}}\left(P\left(d_{\min } \approx 2.8 \AA\right.\right.$, $\left.\left.\mathrm{H} 5_{5-\mathrm{HT}}\right)_{\text {maximum }}<\sim 0.4\right)$ and $\mathrm{P}_{\text {lipid }}-\mathrm{N} 12_{5-\mathrm{HT}}\left(P\left(d_{\text {min }} \approx 3.7 \AA\right.\right.$, $\left.\left.\mathrm{N} 12_{5-\mathrm{HT}}\right)_{\text {maximum }}<\sim 0.3\right)$. No strong preference for $\mathrm{P}_{\text {lipid }}$ was identified for 5- $\mathrm{HT}^{n}$, as all investigated $P\left(d_{\min }\right)$ ' were around 0.1-0.2. $P\left(d_{\min }\right)$ 's for $2 \AA \leq d_{\min } \leq 9 \AA$ are provided in Figure S5.

the charged 5-HT species, the most important interaction is between $\mathrm{P}_{\text {lipid }}$ and $\mathrm{N} 22_{5-\mathrm{HT}}$, followed by $\mathrm{P}_{\text {lipid }}-\mathrm{H} 5_{5-\mathrm{HT}}$. It appears that the $\mathrm{P}_{\text {lipid }}-\mathrm{N} 22_{5-\mathrm{HT}}$ interaction is important for both attracting and anchoring the charged serotonin molecule to the membrane (schematically shown in Figure 4). $\mathrm{P}_{\text {lipid }}-\mathrm{N} 12_{5-\mathrm{HT}}$ interaction plays only a minor role, since the $P\left(d_{\text {min }}\right)$ s are relatively broad, indicating that $\mathrm{N} 12_{5-\mathrm{HT}}$ interacts only weakly with the polar phospholipid atoms. In contrast, for 5-HT lacking the positive charge, only $\mathrm{P}_{\text {lipid }}-\mathrm{H} 5_{5-\mathrm{HT}}$ interaction becomes significant. This is expected, since the 5-HT orientation is opposite to $5-\mathrm{HT}^{+}$(schematically shown in Figure 4). Different interaction patterns are observed for the choline group with 5-HT (Figure S5). Only interactions between the choline group and $\mathrm{N} 12_{5-\mathrm{HT}}$ and to a lesser extent $\mathrm{H}_{5-\mathrm{HT}}$ play a role. However, these distributions are relatively broad, indicating again that these atoms interact only weakly with the choline group. Hence, interactions of the phosphate group and the cationic amine are the dominating contributions for attracting and anchoring the charged species of 5-HT. Despite the dominant role of ionic $\mathrm{P}_{\text {lipid }}-\mathrm{N} 22_{5-\mathrm{HT}}$ contacts, this interaction is not long lived. Thus, if $5 \AA$ is defined as the critical length, the typical lifetime was on the order of ps. This is orders of magnitude faster than the exchange of 5-HT between membrane and bulk (see, e.g., Figure S7), and it follows that 5$\mathrm{HT}$ is mobile in the membrane interface and drifts between different lipid molecules. High mobility of, e.g., small aromatic compounds has also been observed in ${ }^{1} \mathrm{H}$ MAS NOESY NMR studies. $^{2}$

During the absorption of 5-HT, the molecule is dehydrated. To monitor the effect, we have calculated the hydration level of 5-HT (Table S1). As for the definition of the first hydration shell, we used a $3.5 \AA$ cutoff that corresponds to the first minimum in the oxygen-oxygen radial distribution function for water. ${ }^{38}$ The cutoff was applied for water molecules measured from the water oxygen atom to the closest atom of 5-HT. As 5HT diffuses deeper into the bilayer, 5-HT loses 50\% $\left(5-\mathrm{HT}^{+}\right)$ to $\sim 80 \%\left(5-\mathrm{HT}^{n}\right)$ of water molecules in the first hydration shell. Hence, 5-HT remains partially hydrated, and the largest reduction in the hydration level is observed for 5- $\mathrm{HT}^{n}$. This is not surprising since $5 \mathrm{HT}^{n}$ is neutral and its alkyl chain enters deeper into the bilayer than observed for $5-\mathrm{HT}^{+}$. 


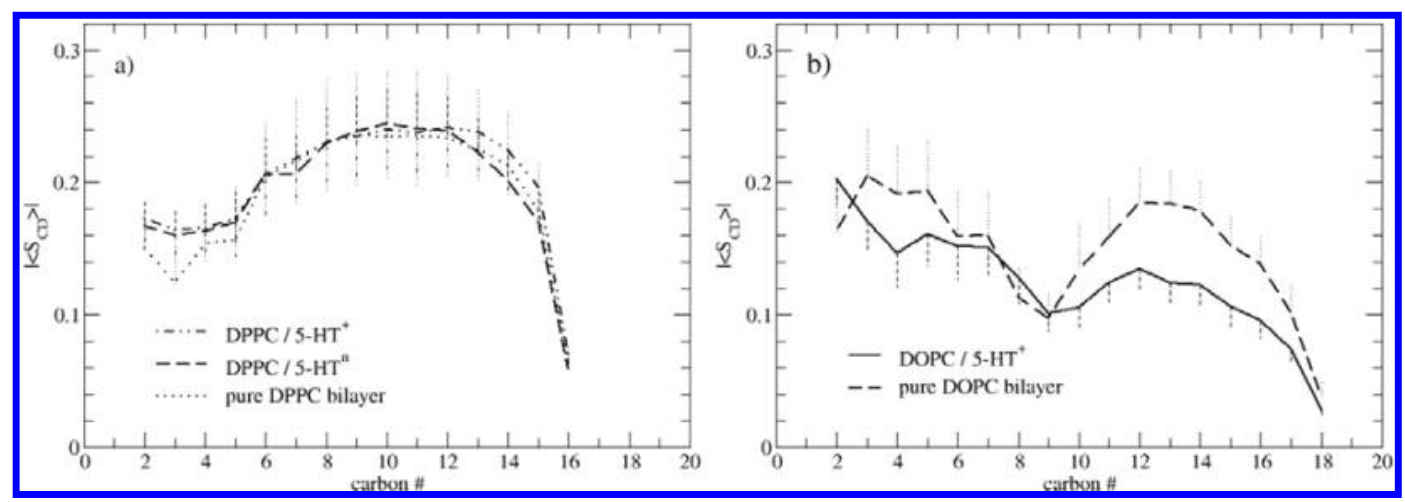

Figure 6. Deuterium order parameter $\left(\left|\left\langle S_{\mathrm{CD}}\right\rangle\right|\right)$ for (a) pure DPPC and DPPC/5-HT and (b) pure DOPC and DOPC/5-HT bilayer membranes. Order parameters are averaged over respectively the last $\sim 100$ and $\sim 70 \mathrm{~ns}$ of the MD trajectory for DOPC $/ 5-\mathrm{HT}^{+}$and $\mathrm{DPPC} / 5-\mathrm{HT}^{+, n}$. Error bars are SEM for four sliding windows in each of the independent simulations. For clarify, only half-error bars are shown.

Effect of Serotonin on Bilayer Structure. The structural effects of 5-HT absorption on the ordering of the alkyl chain were assessed by calculating the order parameter $S_{\mathrm{CD}}$ (defined in Supporting Information). The order profiles for the DPPC/ $5-\mathrm{HT}^{+, n}$ and DOPC/5- $\mathrm{HT}^{+}$systems are shown in Figure 6. For comparison, the order parameter profiles for the pure bilayers are also displayed. The absorption of 5-HT results in changes of the structural ordering in the alkyl chains. These results are in good agreement with the findings of Heimburg and co-workers, who demonstrated that several classes of small molecules, including neurotransmitters, affect membrane properties, resulting in broadening of the melting transition and in melting point depression. ${ }^{52,77}$ For DPPC, 5- $\mathrm{HT}^{+}$causes disorder mainly in the region $\mathrm{C} 12-\mathrm{C} 15$. It appears that, in the $\mathrm{C} 12-15$ region, $5-\mathrm{HT}^{+}$disrupts the lipid structure more than $5-\mathrm{HT}^{n}$. This is in good agreement with the observation that the chain of $5-\mathrm{HT}^{n}$ aligns with the phospholipid alkyl chain as the molecule penetrates deeper into the bilayer. The feature of the order parameter profiles for the DOPC $/ 5-\mathrm{HT}^{+}$is significantly different. Here, the largest effect is seen between $\mathrm{C} 10$ and $\mathrm{C} 17$, i.e., in the region beyond the double bond in the alkyl chains. The order parameter for $\mathrm{C} 12-\mathrm{C} 14$ reduces by $\sim 0.08$ when compared to that of the pure DOPC bilayer membrane.

\section{CONCLUSION}

5-HT was found to interact strongly with the investigated lipid membranes, and the calculated partitioning coefficient was comparable to literature values for highly hydrophobic compounds such as hexanol or heptanol. In contrast to these molecules, 5-HT is a hydrophilic solute with a bulk oil-water partitioning coefficient far below unity. This implies that the affinity of 5-HT for lipid membranes involves direct interactions with the lipid molecules. Such interactions were investigated in the MD simulations, and it was found that attraction between the (cationic) primary amine of 5-HT and the lipid phosphate group constituted the main driving force. This salt-bridge anchored one end of the 5-HT molecule, while the other was pointing inward and typically located at the same depth as the ester bonds of the lipid. The mobility of 5-HT in this position was high, but its affinity for lipids may have been supplemented by hydrophobic effects, as it was partially dehydrated. The importance of the salt bridge was further illustrated by a distinctive change in the mode of interaction upon deprotonation of 5-HT. Thus, the neutral form turned around so the primary amine points toward the membrane core, and also moved to a slightly deeper average position.
Insertion of 5-HT (particularly the cationic form) into the membrane interface decreased lipid chain ordering. This work was motivated by recent suggestions of "non-specific" effects of serotonin in neural transmission (see Introduction), which rely on the transmitter molecule's interaction with the lipid matrix of the synaptic membrane. Obviously, results from simple model systems like the ones studied here can provide only circumstantial evidence, but the distinctive affinity for membranes and the concomitant structural perturbation appear to be necessary premises for membrane-based effects of 5-HT in general, and also in line with the two specific hypotheses reiterated in the Introduction.

\section{ASSOCIATED CONTENT}

\section{S Supporting Information}

Hydration levels of 5-HT as a function $z$; simulation details; results and principles for PMF analyses; estimation of partitioning coefficient from DSC data; simulation results of pure DPPC and DOPC bilayers; scatter plot of distance of $\mathrm{O}_{5-\mathrm{HT}}(z)$ as a function of $\mathrm{N} 22_{5-\mathrm{HT}}(z)$; probability distributions of minimum distance between $\mathrm{P}_{\text {lipid }} / \mathrm{N}_{\text {lipid }}$ and selected 5-HT atoms (N12, N22, and H5) for DPPC/5- $\mathrm{HT}^{+}, \mathrm{DOPC} / 5-\mathrm{HT}^{+}$, and $\mathrm{DPPC} / 5-\mathrm{HT}^{n}$; and simulation results for intermittent changes of 5-HT charge. This material is available free of charge via the Internet at http://pubs.acs.org.

\section{AUTHOR INFORMATION}

\section{Corresponding Author}

ghp@kemi.dtu.dk; pwesth@ruc.dk

\section{Notes}

The authors declare no competing financial interest.

\section{ACKNOWLEDGMENTS}

This work was supported by grants from the Lundbeck Foundation, the Danish Research Agency (Grant 272-060505), and the Danish National Research Foundation through the establishment of MEMPHYS, Center for Biomembrane Physics. Simulations were performed at the Danish Center for Scientific Computing at the University of Southern Denmark.

\section{REFERENCES}

(1) Schreier, S.; Malheiros, S. V. P.; de Paula, E. Biochim. Biophys. Acta 2000, 1508, 210-234.

(2) Scheidt, H. A.; Huster, D. Acta Pharmacol. Sin. 2008, 29, 35-49. 
(3) Nury, H.; Van Renterghem, C.; Weng, Y.; Tran, A.; Baaden, M.; Dufresne, V.; Changeux, J.-P.; Sonner, J. M.; Delarue, M.; Corringer, P. I. Nature 2011, 469, 428-431.

(4) Hemmings, H. C., Jr.; Akabas, M. H.; Goldstein, P. A.; Trudell, J. R.; Orser, B. A.; Harrison, N. L. Trends Pharmacol. Sci. 2005, 26, 503510.

(5) Cantor, R. S. Biochemistry 1997, 36, 2339-2344.

(6) Turkyilmaz, S.; Mitomo, H.; Chen, W.-H.; Regen, S. L. Langmuir 2010, 26, 5309-5311.

(7) Bezrukov, S. M. Curr. Opin. Colloid Interface Sci. 2000, 5, 237243.

(8) Weinrich, M.; Rostovtseva, T. K.; Bezrukov, S. M. Biochemistry 2009, 48, 5501-5503.

(9) Cantor, R. S. Chem. Phys. Lipids 1999, 101, 45-56.

(10) Mouritsen, O. G.; Bloom, M. Annu. Rev. Biophys. Biomol. Struct. 1993, 22, 145-171.

(11) Harroun, T. A.; Heller, W. T.; Weiss, T. M.; Yang, L.; Huang, H. W. Biophvs. I. 1999, 76, 937-945.

(12) Søgaard, R.; Ebert, B.; Klaerke, D.; Werge, T. Biochim. Biophys. Acta 2009, 1788, 1073-1080.

(13) Søgaard, R.; Werge, T. M.; Bertelsen, C.; Lundbye, C.; Madsen, K. L.; Nielsen, C. H.; Lundbæk, J. A. Biochemistry 2006, 45, 1311813129.

(14) Yang, L.; Sonner, J. M. Anesthesia Analoesia 2008, 107, 868874.

(15) Milutinovic, P. S.; Yang, L.; Cantor, R. S.; Eger, E. I.; Sonner, J. M. Anesthesia Analgesia 2007, 105, 386-392.

(16) Mohr, J. T.; Gribble, G. W.; Lin, S. S.; Eckenhoff, R. G.; Cantor, R. S. I. Med. Chem. 2005, 48, 4172-4176.

(17) Cantor, R. S. Biochemistry 2003, 42, 11891-11897.

(18) Wang, C.; Ye, F.; Velardez, G. F.; Peters, G. H.; Westh, P. J. Phys. Chem. B 2011, 115, 196-203.

(19) Peters, G. H. Computer Simulations: A tool for investigating the function of complex biological macromolecules. In Enzyme functionality: Design, engineering, and screening; Svendsen, A., Ed.; Marcel Dekker, Inc.: New York, 2004; pp 97-147.

(20) Peters, G. H. Recent Res. Devel. Biophvs. 2004, 3, 501-526.

(21) Ash, W. L.; Zlomislic, M. R.; Oloo, E. O.; Tieleman, D. P. Biochim. Biophys. Acta 2004, 1666, 158-189.

(22) Stouch, T. R. Prog. Colloid Polvm. Sci. 1997, 103, 116-120.

(23) Pandit, S. A.; Chiu, S. W.; Jakobsson, E.; Grama, A.; Scott, H. L. Biophys. J. 2008, 24, 6858-6865.

(24) Bennett, W. F.; MacCallum, J. L.; Tieleman, D. P. J. Am. Chem. Soc. 2009, 131, 1972-1978.

(25) Li, C.; Yi, M.; Hu, J.; Zhou, H. X.; Cross, T. A. Biophys. J. 2008, 94, 1295-1302.

(26) Johansson, A. C.; Lindahl, E. Proteins 2008, 70, 1332-1344.

(27) MacCallum, J. L.; Bennett, W. F.; Tieleman, D. P. Biophys. J. 2008, 94, 3393-3404.

(28) Tu, K.; Tarek, M.; Klein, M. L.; Scharf, D. Biophys. J. 1998, 75, 2123-2134.

(29) Orsi, M.; Sanderson, W. E.; Essex, J. W. J. Phys. Chem. B 2009, 113, 12019-12029.

(30) Available from http://chem2.sis.nlm.nih.gov/chemidplus/.

(31) Pratuangdejkul, J.; Nosoongnoen, W.; Guérin, G.-A.; Loric, S.; Conti, M.; Launay, J.-M.; Manivet, P. Chem. Phys. Lett. 2006, 420, $538-544$.

(32) Sonne, J.; Jensen, M.Ø.; Hansen, F. Y.; Hemmingsen, L.; Peters, G. H. Biophys. I. 2007, 92, 4157-4167.

(33) Humphrey, W.; Dalke, A.; Schulten, K. I. Mol. Graph. 1996, 14, 33-38.

(34) Jørgensen, A. M.; Tagmose, L.; Jørgensen, A. M.; Bøgesø, K. P.; Peters, G. H. ChemMedChem 2007, 2, 827-840.

(35) Jørgensen, A. M.; Tagmose, L.; Jørgensen, A. M.; Topiol, S.; Sabio, M.; Gundertofte, K.; Bøgesø, K. P.; Peters, G. H. ChemMedChem 2007, 2, 815-826.

(36) MacKerell, A. D., Jr.; Bashford, D.; Bellott, M.; Dunbrack, R., Jr.; Evanseck, J.; Field, M.; Fischer, S.; Gao, J.; Guo, H.; Ha, S.; JosephMcCarthy, D.; Kuchnir, L.; Kuczera, K.; Lau, F.; Mattos, C.; Michnick,
S.; Smith, S.; Stote, R.; Straub, J.; Watanabe, M.; WiorkiewiczKuczedra, J.; Yin, D.; Karplus, M. J. Phys. Chem. B 1998, 102, 35863616.

(37) Phillips, J. C.; Braun, R.; Wang, W.; Gumbart, J.; Tajkhorshid, E.; Villa, E.; Chipot, C.; Skeel, R. D.; Kale, L.; Schulten, K. J. Comput. Chem. 2005, 26, 1781-1802.

(38) Jorgensen, W. L.; Chandrasekhar, J.; Medura, J. D.; Impey, R. W.; Klein, M. L. I. Chem. Phvs. 1983, 79, 926-935.

(39) Nagle, J. F.; Zhang, S.; Tristram-Nagle, S.; Sun, W.; Petrache, H. I.; Suter, R. M. Biophvs. I. 1996, 70, 1419-1431.

(40) Essmann, U.; Perera, L.; Berkowitz, M. L.; Darden, T.; Lee, H.; Pedersen, L. G. L. Chem. Phys. 1995, 103, 8577-8593.

(41) Peters, G. H.; Hansen, F. Y.; Moeller, M. S.; Westh, P. J. Phys. Chem. B 2009, 113, 92-102.

(42) Grossfield, A. WHAM: the weighted histogram analysis method, Version 2.0.6; 2012 (http://membrane.urmc.rochester.edu/content/ wham).

(43) Neale, C.; Bennett, W. F. D.; Tieleman, D. P.; Pomes, R. J. Chem. Theorv Comput. 2011, 7, 4175-4188.

(44) MacCallum, J. L.; Tieleman, D. P. I. Am. Chem. Soc. 2006, 128, $125-130$.

(45) Hub, J. S.; De Groot, B. L. Proc. Natl. Acad. Sci. U.S.A. 2008, 105, 1198-1203.

(46) Wang, C.; Ge, Y.; Mortensen, J.; Westh, P. J. Phys. Chem. B 2011, 115, 9955-9961.

(47) Westh, P. Biophvs. I. 2003, 84, 341-349.

(48) Kupiainen, M.; Falck, E.; Ollila, S.; Niemela, P.; Gurtovenko, A. A.; Hyvonen, M. T.; Patra, M.; Karttunen, M.; Vattulainen, I. J. Comput. Theor. Nanosci. 2005, 2, 401-413.

(49) Bauer, M.; Megret, C.; Lamure, A.; Lacabanne, C.; Fauranclavel, M. J. I. Pharm. Sci. 1990, 79, 897-901.

(50) Andersen, H. D.; Wang, C.; Arleth, L.; Peters, G. H.; Westh, P. Proc. Natl. Acad. Sci. U.S.A. 2011, 108, 1874-1878.

(51) Chattopadhyay, A.; Rukmini, R; Mukherjee, S. Biophys. J. 1996, $71,1952-1960$

(52) Seeger, H. M.; Gudmundsson, M. L.; Heimburg, T. J. Phys. Chem. B 2007, 111, 13858-13866.

(53) Mastrangelo, S. V. R.; Dornte, R. W. L. Am. Chem. Soc. 1955, 77, $6200-6201$.

(54) Katz, Y.; Diamond, J. M. I. Membr. Biol. 1974, 17, 101-120.

(55) Rowe, E. S.; Zhang, F. L.; Leung, T. W.; Parr, J. S.; Guy, P. T. Biochemistry 1998, 37, 2430-2440.

(56) Kamaya, H.; Kaneshina, S.; Ueda, I. Biochim. Biophys. Acta 1981, 646, 142.

(57) Leo, A.; Hansch, C.; Elkins, D. Chem. Rev. 1971, 71, 525-616.

(58) Amidon, G. L.; Yalkowsky, S. H.; Leung, S. J. Pharm. Sci. 1974, 63, $1858-1866$

(59) Westh, P.; Trandum, C.; Koga, Y. Biophvs. Chem. 2001, 89, 5363.

(60) Westh, P.; Trandum, C. Biochim. Biophys. Acta 1999, 1421 261-272.

(61) Kang, S.; Green, J. P. Nature 1969, 222, 794-795.

(62) Hansch, C.; Leo, A.; Hoekman, D. Exploring QSAR, Hydrophobic, electronic and steric constants; American Chemical Society: Washington, DC, 1995; Vol. 2.

(63) Tatsumi, H.; Ueda, T. I. Electroanal. Chem. 2011, 655, 180-183.

(64) Sonne, J.; Hansen, F. Y.; Peters, G. H. I. Chem. Phvs. 2005, 122, $1-9$.

(65) Pedersen, U. R.; Peters, G. H.; Westh, P. Biophys. Chem. 2007, 125, 104-111.

(66) Pedersen, U. R.; Leidy, C.; Westh, P.; Peters, G. H. Biochim. Biophvs. Acta 2006, 1758, 573-582.

(67) Chiu, S. W.; Jakobsson, E.; Subramanian, S.; Scott, H. L. Biophvs. I. 1999, 77, 2462-2469.

(68) De Vries, A. H.; Mark, A. E.; Marrink, S. J. J. Phys. Chem. B 2004, 108, 2454-2463.

(69) Douliez, J.-P.; Leonard, A.; Dufourc, E. J. Biophvs. I. 1995, 68, 1727-1739.

(70) Seelig, A.; Seelig, J. Biochemistry 1974, 13, 4839-4845. 
(71) Mehler, E. L.; Fuxreiter, M.; Simon, I.; Garcia-Moreno, E, B. Proteins: Struct., Funct. Genet. 2002, 48, 283-292.

(72) Peters, G. H.; Dahmen-Levison, U.; de Meijere, K.; Brezesinski, G.; Toxvaerd, S.; Svendsen, A.; Kinnunen, P. K. I. Langmuir 2000, 16, $2779-2788$

(73) Macartney, D. H. Isr. I. Chem. 2011, 51, 600-615.

(74) Hamilton, J. A.; Cistola, D. P. Proc. Natl. Acad. Sci. U.S.A. 1986, $83,82-86$.

(75) Tieleman, D. P. Clin. Exp. Pharmacol. Physiol. 2006, 33, 893903.

(76) Nagle, J. F.; Tristram-Nagle, S. Biochim. Biochim. Acta 2000, $1469,159$.

(77) Heimburg, T.; Jackson, D. Biophys. J. 2007, 92, 3159-3165. 